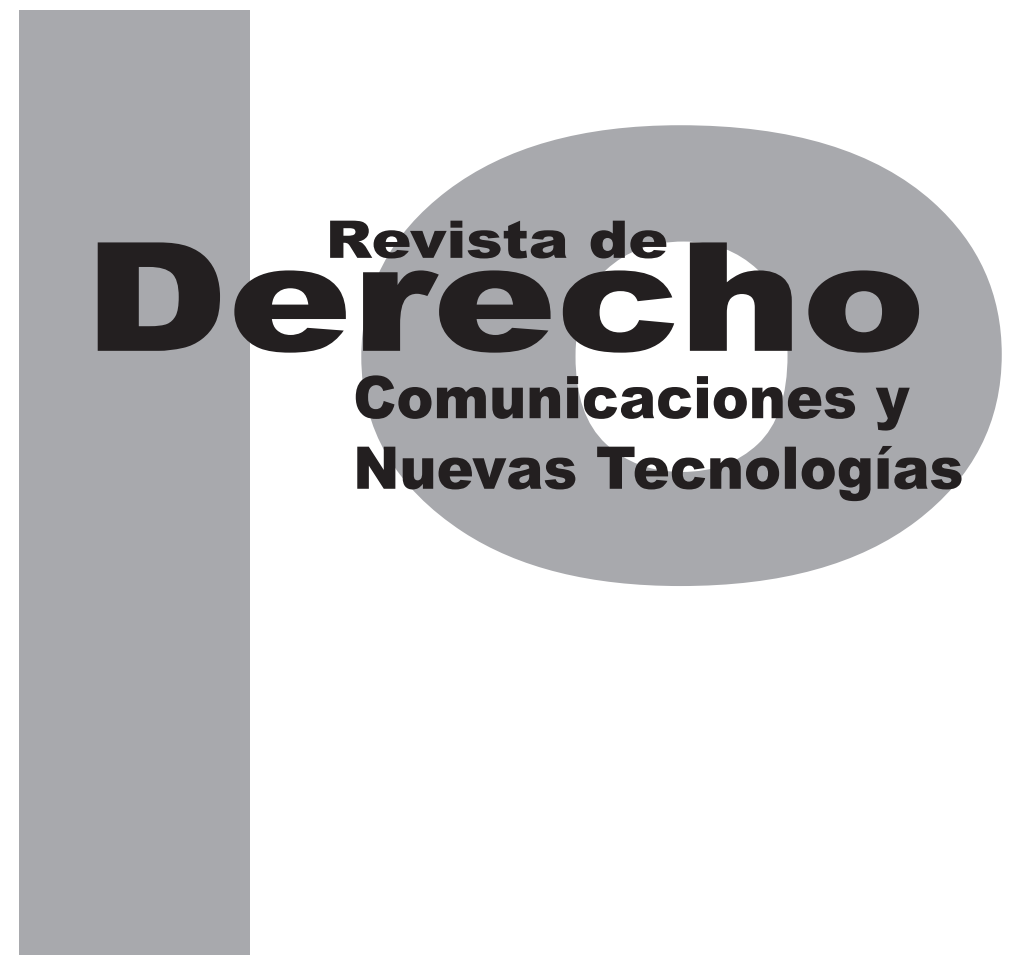

\title{
LAS RESTRICCIONES VERTICALES EN LA POLÍTICA DE COMPETENCIA COLOMBIANA. PARÁMETROS DE ANÁLISIS DE CASOS
}

\author{
LAURA MARCELA RUIZ
}

Revisión de tema

Universidad de los Andes

Facultad de Derecho

Revista de Derecho, Comunicaciones y Nuevas Tecnologías

No. 11, Enero - Junio de 2014. ISSN 1909-7786 


\section{Las restricciones verticales en la política de competencia colombiana. Parámetros de análisis de casos}

\section{Resumen}

Este trabajo plantea un análisis conceptual de la teoría de las restricciones verticales, y hace énfasis en la discusión de la afectación de la eficiencia económica que este tipo de acuerdos conlleva. Asimismo, hace una revisión del tratamiento normativo de las restricciones verticales en diferentes jurisdicciones, incluyendo la colombiana. Con base en el análisis del caso Ibope, y de los demás conceptos analizados, se proponen unos criterios mínimos de análisis para casos de restricciones verticales en la jurisdicción colombiana.

Palabras clave: Política de competencia, restricciones verticales.

\section{Vertical restraints on competition policy in Colombia. Case analysis parameters}

\section{Abstract}

This work proposes a conceptual analysis of the theory on vertical restraints, emphasizing on the debate about the implications of such agreements on economic efficiency. Moreover, it provides an overview of the regulatory treatment of vertical restraints in different jurisdictions including that of Colombia. Based on the IBOPE case study and the supplementary concepts analyzed, this work proposes a minimum criterion of analysis for cases on vertical restraints in the Colombian jurisdiction.

Keywords: Competition policy, vertical restraints.

\section{As restrições verticais na política de concorrência colombiana. Parâmetros de análise de casos}

Resumo

Este trabalho apresenta uma análise conceitual da teoria das restrições verticais, e enfatiza a discussão da afetação da eficiência econômica que este tipo de acordo implica. Também, faz uma revisão do tratamento normativo das restrições verticais em diferentes jurisdições, incluindo a colombiana. Com base na análise do caso lbope, e dos demais conceitos analisados, são propostos uns critérios mínimos de análise para casos de restrições verticais na jurisdição colombiana.

Palavras-chave: Política de concorrência, restrições verticais. 


\section{SUMARIO}

Introducción - I. DEFINICIONES - A. Restricción vertical - 1. Tipos de restricciones verticales - B. Integración vertical - II. LAS RESTRICCIONES VERTICALES EN EL CONTEXTO COLOMBIANO - A. Normatividad aplicable - B. Cómo es el análisis de casos de restricciones verticales en Colombia - III. ELEMENTOS DEL ANÁLISIS - A. Posición de dominio - B. Mercado relevante - C. Presencia de un acuerdo - D. Contestabilidad del mercado - E. Análisis de la industria específica - IV. RESTRICCIONES VERTICALES EN OTROS PAÍSES - A. Estados Unidos - 1. Caso de la Federal Trade Commission (FTC) v. Toys "R" Us - B. Comunidad Europea - C. Chile - V. CASO IBOPE - A. Hechos - 1. El mercado de la pauta publicitaria en televisión - 2. Mercado de medición de audiencia - B. Conducta - C. Análisis de la SIC - D. Análisis del caso a la luz de los conceptos expuestos - VI. LINEAMIENTOS QUE SE DEBERÍAN TENER EN CUENTA PARA EL ANÁLISIS DE CASOS - VII. CONCLUSIONES - Referencias - ANEXO 1 


\title{
Las restricciones verticales en la política de competencia colombiana. Parámetros de análisis de casos ${ }^{1}$
}

\author{
Laura Marcela Ruiz ${ }^{2}$
}

Introducción

Los individuos y las asociaciones de estos, tales como las familias, se enfrentan en diversas situaciones con otros individuos o con otras familias. Piénsese, por ejemplo, en las familias que van de compras; siempre quieren las frutas más frescas y el mejor producto al menor precio. Por este objetivo tendrán que competir en cierto sentido con las otras familias, pues cada una busca lo que considera mejor para sí misma. Sin embargo, aunque los intereses de las diferentes familias compiten entre sí, la competencia los favorece a todos. Si una familia se aísla de las otras y se vuelve autosuficiente, el esfuerzo requerido será mucho mayor y, seguramente, los resultados no serán los mismos. No es lo mis-

1 Cómo citar este artículo: Ruiz, L. M. (Junio, 2014). Las restricciones verticales en la política de competencia colombiana. Parámetros de análisis de casos. Revista de Derecho, Comunicaciones y Nuevas Tecnologías, 11.

2 Economista y abogada de la Universidad de los Andes. Actualmente es asesora del Ministerio de Hacienda y Crédito Público de Colombia en regulación financiera y proyección normativa. Correo: Imrd_88@ hotmail.com. mo que una familia coseche y procese sus propios alimentos, haga su propia ropa y produzca su propia energía, que si se vale del trabajo de otras familias o individuos que se especializan en estas labores, y simplemente acude al mercado a intercambiar lo que produjo por lo que otros produjeron. Este intercambio de productos y servicios se hace en el mercado, en el cual se enfrentan muchos individuos y asociaciones que toman decisiones de forma independiente y descentralizada, guiadas por los intereses particulares de cada agente (Mankiw, 2004). El mercado es la estructura de organización social donde se tejen acuerdos de intercambio entre individuos o asociaciones de estos, quienes interactúan movidos por la satisfacción de sus necesidades (Williams, 2012).

Los individuos acuden al mercado gozando de total libertad para ofrecer e intercambiar productos que se elaboran con base en la libertad de propiedad privada y de libertad de empresa (Almonacid y García, 1998). El resultado del intercambio es, en la mayoría de los casos, la ob- 
tención de utilidad económica para cada agente del mercado. No obstante, a pesar de que hay libertad de entrada al mercado y de escogencia de los bienes y servicios deseados según el poder adquisitivo de cada agente, la libertad de la que se goza no es absoluta. El mercado requiere reglas para regular los intereses, de forma que no hayan grandes conflictos que puedan estropear la dinámica del mismo. Debido a que lo que es óptimo para un individuo no siempre lo será para otro, las reglas reguladoras del mercado se deben enfocar en el bienestar de todo el mercado, y no solo de individuos particulares. En este sentido, el objetivo de la regulación debe ser el bienestar y la eficiencia del mercado como un todo (Crew y Kleindorfer, 1986).

En economía, el concepto de bienestar es usado para medir qué tan bien se está desenvolviendo una industria, y para esto se tiene en cuenta el bienestar de los diferentes grupos del mercado. Se entiende, por ejemplo, como un grupo el de los consumidores; el bienestar de dicho grupo debe entenderse como la suma del bienestar de cada consumidor individual. Lo mismo se da en el caso del grupo de los productores, en el que el bienestar del grupo está determinado por la suma de cada bienestar individual, que a su vez está definido como el beneficio obtenido por la venta de los bienes (Motta, 2009). Puesto que el papel que desempeñan los consumidores es distinto del que desempeñan los productores, el concepto de bienestar no está definido por el comportamiento de cada grupo particular ni por la distribución del ingreso entre estos, sino que tiene en cuenta el funcionamiento del mercado como una gran estructura; si este es eficiente o no. Al definir un mercado como eficiente se hace referencia a la eficiencia económica, considerada como una propiedad del mercado en la que se evalúa si este está aprovechando de la mejor manera sus recursos. De acuerdo con esto, entre mayor sea la maximización de los recursos escasos, más eficiente será el mercado. Cabe aclarar que esta propiedad no contempla la distribución de los recursos al interior del mercado, pues en dicho caso se estaría hablando de equidad. Tiene en cuenta, en cambio, el funcionamiento del mercado como un ente global (Mankiw).

Como se expuso, los diferentes agentes deben gozar de la libertad de competencia económica, entendida como la libertad de acceder al mercado, ya sea la libertad de ofrecer los bienes o servicios, o la libertad de adquirirlos. Para que estas libertades se puedan garantizar, los agentes requieren reglas que eliminen las conductas que limitan sus libertades, de manera que la eficiencia del mercado no se vea mermada. Según Motta, la política de competencia es el grupo de políticas y leyes que aseguran que la competencia en el mercado no esté restringida, de tal forma que pueda reducir o afectar negativamente el bienestar económico.

En Colombia, la libre competencia es un derecho de carácter constitucional y, en este sentido, las políticas que la protegen se dirigen a evitar que esta libertad se vea restringida. Esta legislación contiene normas sobre prácticas restrictivas de la competencia, esto es, acuerdos anticompetitivos o carteles; actos anticompetitivos; situaciones de abuso de posición dominante, y obli- 
gaciones relacionadas con el control previo de integraciones empresariales (Superintendencia de Industria y Comercio [SIC], Guía sobre aplicación de normas). A su vez, esta legislación declara a la SIC la autoridad única en materia de protección de la competencia. ${ }^{3}$

Entre los acuerdos contemplados por las políticas de competencia se encuentran, entre otros, los acuerdos entre diferentes agentes de una cadena vertical o entre diferentes agentes que ocupan una misma posición en la cadena de producción. Los primeros son conocidos como restricciones verticales, y los segundos como horizontales. En la doctrina sobre restricciones verticales se resalta que no en todos los casos una restricción de este tipo va en contra de la competencia, pues muchas veces la presencia de esta figura permite la maximización de la eficiencia del mercado. Sin embargo, este punto es todavía objeto de debate.

Este trabajo tiene como objetivo analizar el tratamiento que se le da a las restricciones verticales en el contexto colombiano. Para esto, primero, se hará una exposición conceptual del tema, luego se explicará la legislación sobre la materia y cómo es el tratamiento de casos de restricciones verticales en otros países. Posteriormente se expondrá la temática para el contexto colombiano en particular, partiendo del análisis de un caso ya sancionado por la SIC: el caso Ibope. Por último, se establecerán unos lineamientos

3 Son reguladas, en conjunto, por la Ley 155/1959, el Decreto 2153/1992 y la Ley 1340/2009. que deben tenerse en cuenta en el análisis de casos similares.

\section{DEFINICIONES}

\section{A. Restricción vertical}

En la mayoría de los mercados, los bienes no son vendidos a los consumidores finales directamente por el fabricante; este proceso se hace a través de intermediarios y vendedores minoristas. La participación de varios agentes es necesaria, tanto para la producción, como para la venta y distribución del bien final. Esto lleva a que se formen estructuras verticales de producción, conocidas como cadenas verticales. Por ejemplo, para la producción de botellas de plástico, una empresa produce la materia prima, como el polipropileno; otra suministra los colorantes para este polímero. Después, otra empresa fabrica las botellas que, posteriormente, serán vendidas a la compañía que envasará en estas sus productos. Esta es una estructura clásica de una cadena vertical de producción puede haber variaciones, dependiendo de la industria-. Ahora, una vez producido el bien final, las bebidas terminan en manos de los consumidores finales a través de una cadena de distribución y venta. Entonces, la empresa fabricante vende su producto a distribuidores mayoristas, quienes, a su vez, lo venden a las grandes superficies o a los vendedores minoristas, como, por ejemplo, las tiendas al detal.

Puesto que cada uno de los agentes de una cadena vertical busca satisfacer sus propios 
intereses, y evitar las pérdidas de utilidad, generalmente se establecen acuerdos entre los diferentes eslabones de la cadena, que ayudan a los agentes a protegerse de las dinámicas del mercado que les pueden resultar perjudiciales (Shy, 2005). Estos acuerdos son conocidos como restricciones verticales. Debido a que lo que es óptimo para un agente del mercado no necesariamente es óptimo para otro, en muchos casos las restricciones verticales son usadas como mecanismo de protección ante los posibles efectos de las decisiones de la otra empresa (Rey, 2008). Los acuerdos entre empresas o agentes económicos relacionados verticalmente pueden tener efectos a favor o en contra de la eficiencia del mercado.

Sobre este punto se ha tejido una larga discusión entre los académicos, quienes discuten sobre la legalidad de este tipo de acuerdos. Por un lado, hay quienes consideran que los acuerdos verticales son distintos de los acuerdos entre diferentes firmas que compiten entre sí, pues son usados solo cuando ayudan al incremento de la eficiencia de la cadena vertical. Por tanto, los entes reguladores deben permitir que los agentes establezcan este tipo de acuerdos. Por otro lado, hay quienes creen que cualquier acuerdo que limite desde algún punto de vista la libertad de las partes restringe la competencia y, por lo tanto, deberá ser prohibido (Butz y Kleit).

\section{Tipos de restricciones verticales}

Hay varias clases de restricciones verticales que son consideradas las más comunes. Sin embargo, no hay una lista exhaustiva, pues el naci- miento de un acuerdo tiene características muy específicas que dependen del mercado y del contexto en el que se establezca. En general, hay dos grandes grupos de restricciones verticales, unas se relacionan con los precios, y otras con la limitación de la libertad de alguna de las partes. En el primer grupo están los precios no lineales o tarifas de dos partes, los descuentos por cantidad, entre otros. El segundo grupo incluye restricciones como el mantenimiento del precio de reventa, las cláusulas de exclusividad, la fijación de cantidades, entre otras (Rey).

Precios no lineales: Según esta clase de acuerdos, las partes convienen en que el precio de la venta siempre será el mismo sin importar la cantidad comprada, sumado a un monto por unidad adquirida. Por lo tanto, si el vendedor minorista no le compra nada al productor, la cuota que se tendrá que pagar en el mes, por ejemplo, será del monto fijo. Si compra dos bultos del producto, el costo será el monto fijo más el monto por dos unidades. El objetivo de este acuerdo es incentivar al vendedor minorista a que le compre al productor, pues entre mayor sea la cantidad comprada, el precio -comparativamente-será menor.

Descuentos por cantidad: Estos acuerdos suponen que entre mayor cantidad de producto se adquiera, mayor será el descuento que el productor haga al distribuidor. El efecto de este acuerdo es el mismo que el del acuerdo anterior, pues entre más grande sea la cantidad que se compra, más barata resulta la compra en promedio. 
Mantenimiento del precio de reventa: Estos acuerdos suponen la fijación del precio que se ofrece al consumidor final por el producto. El precio no es determinado por el distribuidor; se acuerda previamente entre el distribuidor y el productor. Este acuerdo, normalmente, se estipula para que el productor pueda influir en el beneficio del distribuidor, pues sin este el productor no tendría conocimiento de las decisiones del distribuidor.

Cláusulas de exclusividad: Mediante este tipo de acuerdos las acciones de algunos de los agentes de la cadena vertical se ven limitadas. Hay, por ejemplo, acuerdos de exclusividad territorial mediante los cuales el distribuidor, en algunos casos, es el único que vende el producto en cierto territorio. También pueden ser acuerdos de exclusividad de producto, entre otros.

Fijación de cantidades: Mediante estos acuerdos el fabricante fija un tope máximo o mínimo de unidades que el distribuidor le puede comprar. Esto permite exclusividad para su producto, o el aumento de sus ventas en caso de que su producto sea bien reconocido por los consumidores finales.

\section{B. Integración vertical}

Las actividades verticalmente relacionadas, separadas en diferentes agentes, pueden combinarse e integrarse bajo un solo techo, en una sola empresa (Kwoka y White, 2009). Piénsese, por ejemplo, en una empresa que produce bebidas energéticas. Esta empresa puede decidir, a su vez, comprar la empresa de distribución de su producto, conformando así una sola compañía, que ahora ejerce las dos funciones: fabricación y distribución. En principio, casi cualquier estructura vertical de una empresa ya constituida puede ser agrupada en una sola empresa. Asimismo, una sola empresa puede ser separada en otras distintas, siempre que estén relacionadas verticalmente.

La principal diferencia entre las restricciones y las integraciones verticales radica en que, en las primeras, el acuerdo se da entre dos empresas que se encuentran en eslabones diferentes de la cadena vertical. En una integración vertical, mientras tanto, el resultado es que solo una empresa lleva a cabo diferentes actividades de la cadena de producción y distribución.

La importancia de diferenciar la integración vertical de las restricciones verticales es que, si bien ambos son asuntos cobijados por el régimen de competencia, la normatividad específica aplicable, así como los criterios de análisis de casos, son diferentes. Por ejemplo, la intervención por parte de la SIC en las integraciones verticales es ex ante; en cambio, en acuerdos verticales, generalmente es ex post. Es decir, para el primer caso, la SIC analiza si se puede dar o no la integración, antes de que se lleve a cabo. En el segundo caso, en cambio, la SIC evalúa la legalidad del acuerdo celebrado. 


\section{LAS RESTRICCIONES VERTICALES EN EL CONTEXTO COLOMBIANO}

\section{A. Normatividad aplicable}

En Colombia, la Ley 155 de competencia fue aprobada en 1959. Para ese entonces, la ley se basaba en la coyuntura de la época y, por tanto, sus lineamientos partían de la Constitución de 1886, en especial de su artículo 32. Sin embargo, la legislación que acompañó a esta ley no fue suficiente para su implementación eficaz, difuminándose así su objetivo principal: la protección de la competencia. Luego, con la apertura económica de la década de los noventa, y la implementación de la Constitución Política de 1991, que otorgó rango constitucional al derecho a la competencia, se promulgó el Decreto 2153/1992, el cual aumentó la cobertura en la aplicación de las leyes de competencia, y corrigió algunas imprecisiones (OCDE, 2009).

A pesar de que la legislación sobre la competencia parecía acoplada a las circunstancias de la época, algunas debilidades salieron a la luz. Por esta razón, se hizo imprescindible la expedición de una nueva normativa que se acomodara al nuevo clima inversionista y, en general, al nuevo contexto nacional. Además, el incremento de la competitividad de la economía, definido en el Plan Nacional de Desarrollo 2006-2010, demandó un cambio normativo. Es así como en 2009 se expidió la Ley 1309. Esta ley dispuso que la SIC fuera la autoridad con potestad para aplicar la legislación sobre competencia. En la actualidad, tanto la Ley 155/1959 y el Decreto
2153/1992, como la Ley 1309/2009, están vigentes.

En materia de restricciones verticales, el artículo 1 de la Ley 155/1959 establece la prohibición de

acuerdos o convenios que directa o indirectamente tengan por objeto limitar la producción, abastecimiento, distribución o consumo de materias primas, productos, mercancías o servicios nacionales o extranjeros y, en general, toda clase de prácticas, procedimientos o sistemas con tendencia a limitar la libre competencia y a mantener o determinar precios no equitativos.

Esta norma contempla la presencia de la intencionalidad anticompetitiva, pero no los efectos reales que la conducta tiene. Por esto, el Decreto 2153/1992 amplió el espectro y estipuló que los acuerdos pueden ser contrarios a la libre competencia, tanto por su objeto como por sus efectos. Este decreto, además, estableció una definición que incluye una lista taxativa de acuerdos o carteles, estipulando que por estos se entenderá "todo contrato, convenio, concertación, práctica concertada o conscientemente paralela entre dos o más empresas". Asimismo, en este decreto se incluyó una lista no exhaustiva de acuerdos que se consideran contrarios a la libre competencia.

Puesto que en el Decreto 2153 un acuerdo se puede sancionar, tanto por su intención anticompetitiva, como por los efectos reales que genere, en principio, quien sea acusado bajo esta norma, solo podrá eximirse de responsabilidad si demuestra que no hay un acuerdo y, por tan- 
to, la conducta de la que es acusado tampoco existe. A pesar de esto, en algunos casos la SIC ha establecido que aun con la presencia de un acuerdo, puede argumentarse que, con base en lo estipulado en el artículo 29 del Decreto 2153, esto llevará a un mejoramiento en la eficiencia del mercado. Sin embargo, hay otro camino en el análisis de la conducta: los efectos reales que produce, independientemente de su objetivo. En este caso, los acusados tendrán que argumentar y demostrar que no se produjeron efectos anticompetitivos, o que, por el contrario, el mercado se vio beneficiado en términos de bienestar y eficiencia. Según se observa, estas disposiciones no hacen distinción alguna entre acuerdos verticales $u$ horizontales. Se habla de acuerdos en general.

Además de la legislación sobre competencia, hay normas particulares sobre la materia que dependen de la naturaleza de cada mercado en específico. Estas normas deben ser tenidas en cuenta, pues no todos los mercados se comportan igual. Por tanto, al analizar un caso se debe evaluar la normatividad vigente para el mercado o la industria particular.

En materia procedimental, el artículo 52 del Decreto de 1992 dispone que la SIC tiene la facultad de iniciar una investigación preliminar de oficio, o como resultado de una queja presentada en la división de Promoción de la Competencia, división de su dependencia. Una vez se recibe una denuncia, se entrega al superintendente delegado, quien decide si: i) abrir una averiguación preliminar o ii) desestimar y archivar la denuncia. En caso de que se decida abrir una ave- riguación preliminar, se tramitará en la división de Promoción de la Competencia. En esta etapa, la división dispone de varios procedimientos para determinar si hay méritos suficientes para que se ordene abrir una investigación formal.

Ahora, cuando finalice la averiguación preliminar, el superintendente delegado debe decidir si se abre formalmente una investigación o si se archiva la averiguación preliminar. En caso de que el superintendente decida abrir una investigación formal, se deberá notificar a los involucrados, quienes, dentro de un plazo establecido, podrán aportar y solicitar las pruebas que consideren necesarias. Una vez termina el periodo probatorio, el superintendente delegado para la Promoción de la Competencia presentará al superintendente de industria y comercio un informe motivado en el que exponga el caso y su opinión sobre si se produjo efectivamente la conducta en cuestión.

Este informe motivado se deberá trasladar a los presuntos infractores para que tengan la oportunidad de presentar observaciones dentro de un plazo establecido. Una vez vencido el término para que los denunciados presenten sus observaciones, el superintendente de industria y comercio tomará una decisión definitiva. Contra dicha resolución cabe el recurso de reposición. En la resolución final se puede ordenar el pago de sanciones pecuniarias, el cese o la modificación de la conducta o, alternativamente, establecer que no hubo infracción y, en consecuencia, el archivo de las actuaciones. 
Durante todo el proceso, el superintendente puede ordenar medidas cautelares o provisionales, tales como la suspensión inmediata de conductas que puedan resultar contrarias a las disposiciones. Las medidas cautelares buscan evitar que se produzca o que se siga causando el daño.

Asimismo, el conducto regular de la investigación en temas de competencia puede terminar anticipadamente mediante un acuerdo entre la SIC y el potencial infractor. Este régimen es llamado el ofrecimiento de garantías, es decir, cuando la SIC considera que, a su juicio, el presunto infractor ofrece garantías suficientes de que suspenderá o modificará la conducta por la cual se le investiga. Sin embargo, esto no implica la aceptación de la conducta anticompetitiva. En un caso como estos no se interpone una sanción en cabeza del agente, ni tampoco la autoridad se refiere al fondo del asunto.

\section{B. Cómo es el análisis de casos de res- tricciones verticales en Colombia}

El análisis de casos de restricciones verticales en Colombia no encaja exactamente en alguno de los modelos de análisis que se han establecido en otras legislaciones, tales como los criterios de ilegalidad per se y la "regla de la razón" (rule of reason). La discusión en cuanto a qué análisis se debe aplicar a los casos de restricciones verticales no ha arrojado resultados tan claros, puesto que la legislación colombiana sobre competencia y, en especial, el régimen de responsabilidad administrativa no se adaptan claramente a ninguna de las dos tendencias internacionales (OCDE).
En la discusión están quienes, por un lado, consideran que suponer las restricciones verticales per se ilegales equivale a una presunción de ilegalidad de derecho y solo debe aplicarse a los acuerdos, contratos y conductas descritos en los artículos 47 y 48 del Decreto de 1992. Por lo tanto, esta misma posición cree que tener en cuenta el análisis de la rule of reason, y hacer una evaluación de los efectos a favor y en contra de la competencia, es tener que demostrar la presencia real de efectos dañinos sobre la competencia. En este sentido, la rule of reason debería aplicarse para acuerdos entre empresas y conductas que no figuran de manera explícita en los artículos 47 y 48 del Decreto de 1992, y que se integran en la prohibición general del artículo 1 de la Ley 155/1959 y el artículo 46 del Decreto de 1992.

Sin embargo, esta es solo una posición doctrinaria, pues, al referirse a esta discusión, la SIC ha manifestado que en el ordenamiento jurídico colombiano no se aplica ninguna de las dos teorías acogidas en otros ordenamientos, es decir, que ninguna conducta se supone per se anticompetitiva ni tampoco se tiene en cuenta para el análisis la regla de la razón. A pesar de esto, la SIC advierte que lo que han hecho varios doctrinantes es asimilar las teorías adoptadas en el ámbito internacional a figuras incluidas en el ordenamiento colombiano, tales como la presunción de derecho y la presunción de hecho. Esta aparente incertidumbre genera discusiones como la relacionada con el tipo de análisis y evaluación que se aplica a los carteles, así como los instrumentos probatorios ideales para la defensa de quienes se encuentran investigados por este tipo de conductas. 
Específicamente, en cuanto a las restricciones verticales, la SIC ha aceptado que hay casos en los que la presencia de la restricción vertical puede favorecer la eficiencia y el bienestar del mercado, a diferencia del análisis que la SIC hace sobre acuerdos horizontales, en los que es mucho más restrictiva su apreciación. Sin embargo, tal y como está la regulación en la materia, la SIC puede sancionar un acuerdo vertical anticompetitivo de acuerdo con el artículo 47, sin importar si al hacer un análisis cuidadoso se demuestra que los efectos de dicho acuerdo benefician la competencia del mercado determinado.

En cuanto al análisis de la influencia de un acuerdo vertical sobre la eficiencia del mercado, la SIC ha optado por proponer dos caminos. Primero, cuando el acuerdo no busca la maximización de los recursos ni la optimización del ciclo de producción, toda vez que lo que se propone es imponer condiciones restrictivas al mercado de manera arbitraria, será considerado anticompetitivo. Por otro lado, en los casos en los que el acuerdo no impone condiciones restrictivas al mercado, el análisis será un poco más profundo, pues se tendrán que considerar las condiciones específicas del mercado, de forma que solo con base en las pruebas, los informes y las condiciones específicas del mercado en cuestión, se estructurará la decisión.

\section{ELEMENTOS DEL ANÁLISIS}

\section{A. Posición de dominio}

El artículo 333 de la Constitución Política de CoIombia señala que "el Estado, por mandato de la ley, impedirá que se obstruya o se restrinja la libertad económica, y evitará o controlará cualquier abuso que personas o empresas hagan de su posición dominante en el mercado nacional". Con esta disposición, la intención de la Constitución es definir la posición dominante como el poder que le permite a un ente económico afectar la competencia efectiva en una parte importante del mercado, perturbando la libertad económica y los intereses de los consumidores (Almonacid). De forma que por mandato constitucional las políticas de competencia deberán centrar su atención en los agentes que cuenten con suficiente poder como para afectar las dinámicas de los mercados.

Asimismo, el artículo 2 de la Ley 155/1959 expuso que quienes están sujetas a la vigilancia del Estado en materia de competencia son las empresas que ostentan poder de mercado, pues tienen bajo su control un gran porcentaje de la oferta o la demanda. En los términos de esta disposición, se trata de un poder formal sobre el mercado que pone en cabeza de tales empresas la capacidad para determinar precios e influir radicalmente en el comportamiento de la dinámica del mercado. Sobre el mismo tema, el Decreto 2153/1992 fue un poco más flexible al contemplar que, aunque la participación formal que tenga una empresa en el mercado 
sea poca, materialmente puede tener mucha influencia debido a un control indirecto de elementos vitales para su funcionamiento, caso en el cual es posible hablar de posición dominante. Esta definición -más general que la contenida en la Ley 155/1959- contempla la posibilidad de que haya posición dominante, ya sea por la determinación directa o indirecta de las condiciones del mercado específico.

La Corte Constitucional se ha pronunciado en varias ocasiones sobre la definición de posición dominante. En la Sentencia T-240/1993 se destacó lo siguiente:

La posición dominante de una empresa suele definirse como la posibilidad de ejercer un comportamiento independiente respecto de los precios, condiciones de venta, volúmenes de producción y sistemas de distribución de bienes o de servicios, dado el control que ella puede ejercer sobre una parte significativa del mercado en razón de la magnitud de sus recursos financieros, tecnológicos o del manejo estratégico de las materias primas y demás factores económicos.

Se puede definir entonces que un agente está en posición dominante cuando puede modificar unilateralmente y de forma representativa las condiciones en que se presta el servicio o se vende el bien respectivo, sin consideración de los otros competidores presentes en el mercado. Esta determinación de las condiciones del mercado puede darse tanto indirecta como directamente.

La importancia de la determinación de la presencia de una posición dominante es que la SIC puede abstenerse de conocer casos en los que no se trate de conductas significativas, por no tratarse de empresas con posición dominante. Esto a pesar de que la legislación en Colombia no contempla directrices que sirvan para establecer criterios de evaluación de la tenencia de un poder formal del mercado. En este sentido, el Decreto 2153 dispone que la SIC solo debe dar trámite a aquellas reclamaciones por violaciones a la ley de competencia que sean "significativas" o "importantes".

No obstante, la trascendencia de la actuación no radica en que efectivamente haya, directa o indirectamente, posición de dominio, sino que se abuse de dicha posición. La reglamentación contenida en el artículo 50 del Decreto 2153/1992 establece seis conductas constitutivas de abuso de posición dominante. ${ }^{4}$ Estas conductas contemplan actos que conllevan la eliminación de competidores o el impedimento y la obstrucción del acceso a los mercados y canales de comercialización por parte de agentes interesados en participar. Este impacto negativo es lo que se reprocha, no la posición de dominio en sí misma.

\section{B. Mercado relevante}

El mercado relevante es el mercado de referencia, tanto en términos de producto como en dimensión geográfica, en el cual se desenvuelve una empresa (Diez, 2001). Por medio del análisis del mercado relevante se determina cuál es

4 No obstante, pueden haber conductas atípicas no contempladas en esta norma. No es una lista taxativa. 
el contexto competitivo al que se enfrenta una empresa que sea objeto de investigación. Este análisis se propone identificar, fundamentalmente, tres elementos: i) cuál es el conjunto de productos que compiten entre sí para satisfacer las necesidades de los consumidores; ii) cuál es el conjunto de empresas que pueden ofrecer dichos productos en un plazo relativamente reducido de tiempo, y iii) cuál es el área geográfica en la que las condiciones de competencia para el suministro de dichos productos son suficientemente homogéneas y diferentes de las de otras áreas geográficas próximas (Jiménez y Cañizares, 2005).

La determinación del mercado relevante es un paso previo a cualquier análisis sobre competencia. Este mecanismo permite valorar el carácter competitivo o anticompetitivo de la conducta de una empresa, puesto que funciona como referencia para establecer si, efectivamente, hay un poder de mercado relevante, de forma que dicha conducta pueda estropear la competencia. Además, el mercado relevante también ayuda a definir si la influencia en el mercado es tal que justifique la intervención de la SIC. Por lo tanto, analizar estos elementos sirve para realizar una primera aproximación sobre el posible dominio de la empresa objeto de investigación. Por lo anterior, al abordar el examen sobre las restricciones verticales, es indispensable agotar el análisis de este mecanismo.

En palabras de la SIC, el mercado relevante se refiere, en términos generales, al mercado del producto o servicio, de sus sustitutos y del ámbito geográfico de los competidores potenciales que operan en el lugar donde se da la competencia. Por lo anterior, para determinar su alcance hay que definir el producto o servicio de que se trate, los competidores que elaboran los bienes sustitutos, la región geográfica donde se da la competencia, y las dificultades de acceso al mercado, tales como tecnología, capacidad de planta, costos de transporte, entre otros factores. Para acreditar el cien por ciento del mercado es necesario sumar las participaciones en las ventas de quienes intervienen en la operación, de los competidores y de los productores de bienes y servicios sustitutos ofrecidos (SIC, Concepto 23410).

Como se expuso, para llevar a cabo el análisis del mercado relevante se deben tener en cuenta dos factores: el mercado del producto y la dimensión geográfica en la que la empresa realiza sus operaciones (Diez, 2001). En cuanto al mercado relevante del producto, se deben analizar tres factores: la sustituibilidad de la oferta, ${ }^{5}$ la sustituibilidad de la demanda y la competencia potencial. ${ }^{6}$ Sin embargo, el elemento que normalmente se considera decisivo y determinante es la sustituibilidad de la demanda, debido a que definirla es mucho más práctico en comparación con los otros dos factores (Jiménez y Cañizares).

5 El comportamiento de una empresa se puede ver, asimismo, disciplinado por la posibilidad de que, en respuesta a un incremento de precios, otras empresas decidan comenzar a competir con ella suministrando uno o varios de esos bienes o servicios que el consumidor considera sustitutivos.

$6 \quad$ Un agente se considera competidor potencial si se prueba que tiene la intención, y es factible que haga las inversiones suficientes para entrar en el mercado ante variaciones en los precios del producto. 
La sustituibilidad de la demanda considera cuáles productos son suficientemente similares en cuanto a precio, función y características del producto de la empresa que se pretende investigar, de forma que los usuarios puedan considerar uno sustitutivo del otro. De manera que, en respuesta a un incremento de precios del producto de la empresa $X$, sus clientes decidirán redirigir el consumo hacia otros productos o servicios de las empresas $\mathrm{M}$ y Z por considerarlos sustitutivos, ya sea por razón de sus características técnicas, precios o, en definitiva, por su capacidad para satisfacer una determinada necesidad de forma equiparable. ${ }^{7}$ Para este análisis se deben tener en cuenta criterios de sustituibilidad real y razonable, por ejemplo, realizándose un ejercicio mental mediante el cual se suponga el aumento del precio del producto de la empresa X, y se planteen los potenciales efectos sobre la demanda por parte de los consumidores teniendo en cuenta sus necesidades. Se aplica así un criterio de intercambiabilidad.

Ahora, el mercado geográfico relevante comprende el análisis y la determinación de la zona geográfica en la que la empresa potencialmente investigada desarrolla sus actividades comerciales, y en la que las condiciones de competencia son suficientemente homogéneas. Esta capacidad de un oferente de un producto sobre un área geográfica debe ser determinante en la influencia sobre los precios, así como en el mercado del producto se tienen en cuenta dos elementos: la sustituibilidad de la demanda en

$7 \quad$ En términos económicos este comportamiento se puede definir como "elasticidad cruzada de la demanda". términos geográficos y la sustituibilidad de la oferta. La primera, entendida como la posibilidad de que los consumidores decidan redirigir su consumo hacia productores de ese mismo bien, situados en áreas geográficas vecinas. Y la segunda, definida como la posibilidad de que empresas situadas en áreas geográficas vecinas decidan entrar a competir en la zona donde se han incrementado los precios.

\section{Presencia de un acuerdo}

Como se expuso, en la legislación colombiana están prohibidos los acuerdos o convenios que directa o indirectamente tengan por objeto limitar la producción, abastecimiento, distribución o consumo de materias primas, productos, mercancías o servicios nacionales o extranjeros, y, en general, toda clase de prácticas, procedimientos o sistemas tendientes a limitar la libre competencia y a mantener o determinar precios inequitativos. El Gobierno, sin embargo, podrá autorizar la celebración de acuerdos o convenios que, a pesar de limitar la libre competencia, tengan por fin defender la estabilidad de un sector básico de la producción de bienes o servicios de interés para la economía general.

Según el artículo 45 del Decreto 2153/1992, se entiende por acuerdo todo contrato, convenio, concertación, práctica concertada o conscientemente paralela entre dos o más empresas. Para que pueda determinarse la configuración de un acuerdo potencialmente contrario a la libre competencia, dicho acuerdo debe ser entre empresas. Para este efecto, se entiende por empresa toda persona que presta servicios de 
manera organizada bajo la modalidad de actividad económica (SIC, Resolución 8233), y para lo cual dichas personas disponen de un conjunto de bienes y recursos (SIC, Resolución 7950).

Debe tenerse en cuenta que la normatividad colombiana sobre prácticas comerciales anticompetitivas es aplicable a todos los agentes económicos participantes en el mercado, sin importar si se encuentran en una misma posición comercial. Es decir, dos agentes que se encuentran en un mismo eslabón de una cadena vertical de producción encajan en las disposiciones. En efecto, el artículo 45 del Decreto 2153/1992 solo exige que haya dos o más agentes económicos que tengan independencia económica entre sí para que se cumplan los presupuestos del artículo 47 de dicho decreto.

Por el contrario, la SIC no puede sancionar a un agente económico por celebrar un acuerdo contrario a la libre competencia cuando los supuestos de infracción se pretenden contra un solo sujeto de derecho, caso en el que se trataría de acto y no de acuerdo; o cuando se imputa contra entes que no tienen la condición de sujetos de derecho, por ejemplo, agremiaciones sin personería jurídica (SIC, Resolución 23650).

Para imponer sanciones por acuerdos contrarios a la libre competencia no importa la capacidad de influencia de las empresas en las condiciones del mercado, ya que la norma que regula la materia no exige para su configuración que el infractor esté en posición de domino (SIC, Resolución 0670). Sin embargo, como se expuso, la SIC puede decidir si investiga o no una conducta teniendo en cuenta la influencia en el mercado.

Para que la SIC investigue y sancione por acuerdos contrarios a la libre competencia es irrelevante si el acuerdo es de tipo vertical u horizontal, pues, como se expuso, el artículo 47 del Decreto 2153/1992 se refiere de manera general a los acuerdos, sin hacer distinción entre horizontales o verticales (SIC, Resolución 21821). Ahora, el acuerdo debe ser bilateral, es decir, entre por lo menos dos empresas que puedan considerarse sujetos de derecho diferentes (SIC, Resolución 23652). Además, se debe acreditar una voluntad exterior que permita colegir un comportamiento de agrupación de objetivos y finalidades que se identifiquen entre sí, es decir, una actuación conjunta y mancomunada. Un acuerdo celebrado en los términos expuestos es requisito esencial para hablar de restricciones verticales en la legislación colombiana.

\section{Contestabilidad del mercado}

Un mercado contestable es aquel que, a pesar de tener pocos competidores, siempre es susceptible a la entrada de otros competidores; en consecuencia, su dinámica se asemeja a un mercado competitivo. Esto previene que haya monopolio en el mercado y asegura que los productos tengan precios competitivos y calidad. Esta teoría fue planteada inicialmente en 1982 por los economistas William Baumol, John Panzar y Robert Willig, quienes señalaron que es posible que un mercado en el que hay solo una empresa funcione en forma competitiva, 
es decir, igual que si hubiera muchas empresas compitiendo fuertemente (Baumol, 1982). Si hay un escenario llamativo para que una empresa se introduzca fácilmente en el mercado, cobre un precio menor que la empresa que ya se encuentra allí, obtenga utilidades y después tenga la posibilidad de salir rápidamente antes de que la otra empresa ajuste sus precios, lo va a hacer cada vez que tenga la oportunidad. Esto es lo que se espera que haga una empresa con un comportamiento "normal", que quiere maximizar su utilidad, incluso si dicha oportunidad desaparece después de entrar en el mercado. Esta posibilidad de entrada de competidores disciplina a la empresa que ya se encuentra en el mercado, de forma que se comporta competitivamente sin que entre en el juego otro competidor (Agostini).

Para que haya una amenaza latente de entrada de otros competidores se deben cumplir ciertas condiciones. La primera, que las empresas entrantes no enfrenten ninguna desventaja respecto de aquellas que ya se encuentran en el mercado. Esta condición sugiere que la empresa entrante debe tener acceso a la misma tecnología, precios de insumos e información a los que tiene acceso la empresa "antigua" en el mercado. En otras palabras, no debe haber barreras de entrada. La segunda condición es que no debe haber costos hundidos, ${ }^{8}$ por tanto los costos asociados a la entrada en el mercado son recuperables. La tercera, que el tiempo ne-

8 Un "costo hundido" es un costo irrecuperable en el que ya se ha incurrido, y que no es relevante para la toma de decisiones de producción. cesario para entrar en el mercado sea menor al tiempo que se demora la empresa "antigua" en ajustar los precios. ${ }^{9}$

Debido a la naturaleza de un mercado contestable, no puede haber ningún tipo de ineficiencia cuando el mercado se encuentre en equilibrio. Ello se debe a que cualquier beneficio superior al normal, al igual que cualquier costo innecesario, constituye un atractivo adicional para la entrada de nuevas empresas. Con base en la teoría de los mercados contestables, en el caso de acuerdos supuestamente contrarios a la libre competencia se puede afirmar, en algunos eventos, que es imposible que se ejerza poder de mercado, pues la adversidad del mercado lo impide. Porque, de acuerdo con la teoría, no hay barreras de entrada de nuevos competidores al mercado.

\section{E. Análisis de la industria específica}

Para el análisis de casos de restricciones verticales, además de la normativa nacional en materia de protección de la competencia, deben tenerse en cuenta las características específicas de cada mercado. Por lo tanto, debe analizarse la estructura del mercado determinado, cómo ha sido el comportamiento de los agentes, la legislación específica para el mercado, los acuerdos regulatorios surgidos de la iniciati-

\footnotetext{
9 Los mismos autores de la teoría señalan que la presencia de costos hundidos, incluso pequeños, puede eliminar la posibilidad de que una empresa entrante obtenga utilidades positivas antes de que las empresas pertenecientes al mercado respondan. De igual forma, si el tiempo que toma entrar en el mercado es mayor que el tiempo que le toma ajustar su precio a los agentes que ya se encuentran operando allí, el precio de equilibrio será superior al competitivo.
} 
va privada que ayudan a regular las relaciones entre sus agentes, entre otros factores contextuales relevantes.

\section{RESTRICCIONES VERTICALES EN OTROS PAÍSES}

\section{A. Estados Unidos}

Desde hace mucho tiempo las restricciones verticales han estado contempladas en la legislación estadounidense sobre protección de la competencia. Sin embargo, esta legislación no ha sido consistente, y ha variado con el tiempo en la mayoría de los temas. Una excepción a esta dinámica es la figura del mantenimiento del precio de reventa, pues siempre se ha presumido que una práctica que encaja en esta figura es siempre ilegal. En 1920, casos como los de Colgate y Standard Oil, relacionados con restricciones verticales, fueron analizados bajo el método de caso por caso. Esta metodología se siguió en el caso White Motor, de 1963, en el cual la Corte Suprema estableció que, puesto que se sabía muy poco del impacto real de "territorios exclusivos", la legalidad de los pactos debía ser determinada solo en un juicio, y no per se. A pesar de esta posición, en 1967 la Corte dictaminó que las restricciones verticales se entenderían per se ilegales. Esta postura radical fue criticada, pero solo se logró atenuar hasta 1977, cuando en el caso GTE Sylvania se estableció que los efectos de las restricciones verticales deberían ser evaluados y analizados bajo la regla de la razón. A pesar de esto, casos que trataban cuestiones como el mantenimien- to del precio de reventa se siguieron entendiendo como ilegales per se. Tiempo después, con la publicación en 1985 de Vertical Restraints Guidelines, se aceptó que en algunos casos las restricciones verticales pueden establecerse en pro de la competencia del mercado. Este último cambio se dio bajo el Gobierno de Reagan. En 1996, nuevamente se dio un cambio en la forma de análisis de los casos de restricciones verticales, pues volvió a hacerse uso de la regla de la razón. Este cambio fue impulsado por Robert Pitofsky. Esta perspectiva fue confirmada en el caso de la Federal Trade Commission (FTC) versus Toys "R" Us, de 1996 (Rey).

\section{Caso de la Federal Trade Commission (FTC) v. Toys "R" Us}

En este caso, Toys "R" Us estableció acuerdos con varios productores de juguetes para que no vendieran sus productos a varios almacenes. El acuerdo fue entre Toys " $R$ " Us y sus principales proveedores, dentro de los que se encontraban Mattel, Fisher Price y Tyco, entre otros. En este acuerdo, además, se establecía que los productos exclusivos o especiales fabricados por estos productores de juguetes serían distribuidos, primero, solo por Toys "R" Us, para observar el comportamiento de la demanda. Los productos solo podían ser vendidos a otras tiendas si estas compraban las líneas completas, y no solo unos productos seleccionados. La forma de presionar a los productores fue la advertencia de Toys "R" Us según la cual dejarían de comprar los productos en caso de que fueran distribuidos a otros almacenes. Según la FTC, este acuerdo 
fue tan efectivo que hubo una disminución notoria en la venta de juguetes de los productores a otras jugueterías. Por ejemplo, las ventas de Mattel a otras jugueterías pasaron de veintitrés millones de dólares en 1991, a 7,5 millones de dólares en 1993. Debido a este acuerdo y a sus notables efectos, en 1997, 44 estados demandaron a las partes involucradas. En 1999, se llegó a un convenio en el cual las empresas se comprometieron a pagar 56 millones de dólares que serían entregados, una parte en efectivo para gastos de abogados y demás honorarios, y el resto en juguetes de beneficencia. El análisis de este caso marcó una ruptura con las concepciones preestablecidas, pues se llevó a cabo un razonamiento cuidadoso del caso, y no se asumió la conducta como ilegal per se. Además, este caso planteó las bases para que los grandes distribuidores pudieran ser demandados, así su posición en el mercado no fuera extensa, pues su nombre y experiencia llevaban a que sus actuaciones tuvieran efectos en un mercado determinado.

Este caso funcionó como punto de partida para el análisis de otros casos de restricciones verticales, en los que se vieron involucradas grandes empresas. Dentro de estos casos se encuentran, por ejemplo, los Estados Unidos v. Microsoft y Le Page's v. 3M.

\section{B. Comunidad Europea}

En general, en Europa el fin de las políticas de competencia no es protegerla en sí, sino que sirvan como medio para lograr la integración del mercado. La principal estipulación normativa se encuentra en el artículo 81 del European Communities Treaty. Dicho artículo dispone que cualquier acuerdo que pueda afectar el comercio entre los Estados miembros, y que tenga como objeto o como efecto la prevención, restricción o distorsión de la competencia del mercado común, está prohibido. En 1964, en el caso Grundig-Consten, se estableció por primera vez que las restricciones verticales estaban incluidas en lo que dispone el artículo 81, especialmente en su primer numeral. No obstante, hay una excepción en el numeral tercero del mismo artículo, según la cual están permitidos aquellos acuerdos que contribuyan a mejorar la producción o distribución de bienes, o que ayuden a promover el progreso tecnológico o económico, mientras permitan a los consumidores una participación justa en el beneficio final. Respecto de las restricciones verticales, en 1966 se publicó Green Paper on Vertical Restraints in EC Competition Policy, el cual incluía una explicación económica del impacto de las restricciones verticales en la competencia del mercado. Después de la publicación de este documento, en 1990 se expidió el Block Exemption Regime, régimen que contenía los nuevos parámetros que se tendrían en cuenta en las excepciones incluidas en el primer numeral del artículo 81. Según este nuevo régimen, las decisiones sobre la legalidad de un acuerdo no se debían tomar teniendo en cuenta únicamente la naturaleza del acuerdo, sino también las características del mercado específico. Para la mayoría de los casos de restricciones verticales, los problemas de competencia solo pueden surgir si no hay suficiente competencia entre marcas, es decir, si hay un cierto grado de 
poder de mercado en el ámbito del proveedor o del comprador, o en ambos niveles. Por lo tanto, en caso de que no haya tal competencia, la restricción de estos acuerdos es relevante. A pesar de lo anterior, hay ciertos tipos de restricciones verticales que se entienden como violatorias de la competencia per se, y, por tal razón, no podrán ser consideradas excepciones a la norma general. Es el caso del mantenimiento del precio de reventa. Esta posición puede observarse en el caso Pronuptia.

\section{Chile}

En Chile, con el fin de establecer si esta clase de acuerdos son anticompetitivos, se han utilizado varias teorías. Hasta 1988, las comisiones Preventiva Central y Resolutiva tuvieron un criterio común para analizar la legalidad de este tipo de conductas. Es así como en el Dictamen de la Comisión Preventiva Central 618/1987 se declaró:

En suma, solo el que actúa por cuenta del mandante o proveedor puede tener el carácter de agente o distribuidor exclusivo, a diferencia del comprador o comerciante que actúa por cuenta propia, quien al constituirse en comprador único, exclusiva y permanentemente, contraviene las normas del señalado decreto ley, en razón de tratarse de una compra que elimina, en una de las etapas del proceso económico, la pluralidad o multiplicidad de demandantes, acarreando necesariamente una negativa de venta por parte del proveedor o fabricante a todo otro interesado en comprarle [...] Este distribuidor exclusivo no puede concentrar parte importante de la distribución del mismo artículo en su mano.
Esta decisión se asimilaba a la regla de conducta anticompetitiva per se. Sin embargo, esta posición cambió con un caso emblemático sobre acuerdos de distribución exclusiva: el caso Nichimen-Daihatsu, resuelto por la Comisión Preventiva Central por medio del Dictamen 808/1992. En este caso, la Comisión aprobó la distribución exclusiva en el mercado de venta de automóviles con el entendido de que se estimaba que este mercado era lo suficientemente competitivo como para que no fuera posible llevar a cabo una conducta de abuso de posición de dominio, a partir de la práctica de una distribución exclusiva (Salamanca).

Otro caso analizado de forma similar fue el de Esso Chile Petrolera Ltda., sobre la legalidad de ciertos contratos de operación de estaciones de servicio. Este caso fue resuelto mediante Dictamen 1083/1999. En dicho caso se cuestionaban varios contratos: i) un contrato de operación respecto de una estación de servicios de propiedad de Esso Chile, entregada a un tercero para su explotación (dealer), quien adquiría los combustibles marca Esso a dicha compañía y los revendía al consumidor; ii) un contrato de operación de una estación de servicio de propiedad de Esso Chile, la cual se entregaba a un tercero para su explotación y venta de combustibles - de propiedad de la compañía-, pero por cuenta de esta última; iii) un contrato de "tienda de conveniencia" mediante el cual Esso entregó a un operador de Servicentro Esso la licencia para operar una franquicia bajo una marca registrada; iv) un cuarto contrato de distribución y reventa (peddler retail), es decir, un contrato de reventa de combustibles diésel y queroseno en 
el lugar físico del cliente, para altos volúmenes de demanda. En estos contratos de operación, el operador utilizaría la estación de servicios exclusivamente para comerciar y exhibir combustibles y lubricantes suministrados por Esso Chile, limitando así el desarrollo de otra actividad comercial, de forma que los contratos de operación se constituyeron en principales, y los de "tienda de conveniencia" y distribución y reventa, en contratos accesorios. La razón principal de la Comisión Preventiva Central para aprobar la legalidad de estos contratos fue que no contravenían la libre competencia, por cuanto el mercado de la venta de estos productos era un mercado competitivo. También se basó en razones de protección de la marca registrada que amparaba los productos.

Ahora, la jurisprudencia sobre fijación de precios de reventa (FPR), en general, no ha aprobado esta conducta. Ha utilizado como primer elemento de juicio la naturaleza de la relación comercial entre el productor, quien impone el precio de reventa, y el distribuidor, quien debe implementar el precio fijado. Si la relación comercial del distribuidor con el productor es de comisionista, la FPR tiende a ser validada y no sancionada. Se argumentó en los dictámenes y resoluciones que si el distribuidor actuaba por cuenta del productor, lo que está directamente relacionado con la figura legal del mandato mercantil, constituía una forma de integración vertical que no era posible intervenir. Por otra parte, en caso de que los bienes sean vendidos por el productor al distribuidor, las comisiones se han inclinado a prohibir esta figura, pues en esta situación hay, claramente, una conducta ilí- cita, ya que se trata de dos entes independientes. Sin perjuicio de lo anterior, la Comisión Resolutiva, por medio de la Resolución 625/2001, declaró ilegal una política de fijación de precios de repuestos originales de vehículos marca Toyota. Sin embargo, esta decisión fue adoptada por tres votos contra dos; una posición minoritaria votó por no declarar ilegal la conducta por la presencia de competencia en el mercado de venta de vehículos.

Este caso está pendiente de resolución ante la Corte Suprema por un recurso interpuesto por Toyota Chile. Con todo, ya en 1992 la Comisión Preventiva Central, mediante Dictamen 833/1992, autorizó un contrato de comisión para concesionarios de vehículos Nissan, aceptando la fijación de condiciones de venta, tales como precios, volúmenes de venta y zonas de mercado. Sostuvo la Comisión: “[...] Lo relevante es que en un determinado mercado haya competencia en la producción o prestación de bienes y servicios, toda vez que es precisamente la libre competencia en las actividades económicas el bien jurídicamente protegido por esta legislación (Decreto Ley 211) y la finalidad última de sus normas". En conclusión, en Chile se ha optado por analizar caso por caso, asimilando su orientación a la de la teoría de la regla de la razón, pues en cada análisis priman los elementos coyunturales del mercado. 


\section{CASO IBOPE}

\section{A. Hechos}

\section{El mercado de la pauta publicitaria en televisión}

El mercado de pautas publicitarias está compuesto por diferentes relaciones en sentido vertical. Según la Resolución de la SIC 20065/2010, en el mercado colombiano, en el primer nivel, se encuentran los anunciantes que son personas naturales o jurídicas, quienes buscan ofrecer su producto o servicio por medio de un mensaje dirigido a un target o público objetivo. Esto se hace a través de la compra de un espacio publicitario en un medio de comunicación, el cual publica un anuncio, que, en sentido amplio, corresponde a la forma que adopta el mensaje publicitario. La transmisión de dicho mensaje se hace por cuenta del anunciante o por intermediación de una agencia de publicidad o de una empresa de medios, quienes desarrollan el producto publicitario o campaña publicitaria, y funcionan como intermediarios en la contratación con los medios de comunicación para la masificación del mensaje. La agencia de publicidad es una persona natural o jurídica, cuyo objeto es la prestación de servicios publicitarios, los cuales incluyen, entre otros, el análisis e investigación de mercados; la formulación, análisis y recomendación de planes de medios; la creación, diseño y producción de piezas y campañas publicitarias; la ordenación y chequeo de la pauta publicitaria a nombre del anunciante, y la ejecución y control de anuncios y campañas publici- tarias de bienes, productos o servicios. Cuando el anunciante tiene lista una campaña publicitaria, por medio de la agencia de publicidad o por su propia cuenta, contrata con las centrales de medios la compra masiva de espacios y tiempos publicitarios (spots), como un servicio de planificación de medios. El otro agente participante en este mercado son los medios de comunicación, que funcionan como el vehículo a través del cual se comunica el mensaje a los potenciales consumidores. Estos últimos agentes tienen como propósito lograr el mayor nivel de audiencia, para llegar al mayor número de personas dentro del público objetivo (ver Figura 1). Los medios de comunicación son el último eslabón de la estructura de mercado antes de llegar a los consumidores finales, quienes establecen los precios de los spots, teniendo en cuenta la franja horaria y la audiencia de un programa específico (SIC, Resolución 20065).

Para los agentes de este mercado es trascendental contar con información acerca de los niveles de audiencia de los medios de comunicación, pues esto es un insumo importante para la determinación del precio del mercado. Generalmente, quienes proporcionan esta información a la industria son las empresas dedicadas a la investigación de medios. Sin embargo, el mercado de la investigación de medición de audiencia es otro, que aunque diferente, no es independiente del mercado de pautas publicitarias.

\section{Mercado de medición de audiencia}

En este mercado están, por un lado, los oferentes, que son las agencias de medición de au- 
diencia, y, por otro, los demandantes del producto de medición, que pueden ser las agencias publicitarias, las centrales de medios, los medios de comunicación y los anunciantes. En este mercado es común que haya solo un producto, es decir, una medición de audiencia en un mismo territorio, pues son estudios que implican costos considerables para la empresa que hace la medición, y no todas las empresas demandantes tienen poder adquisitivo suficiente para tener acceso a un estudio de este tipo. Por lo tanto, una empresa que puede pagarlo solicita el producto, y los otros interesados en el mercado se benefician pero no incurren en los altos costos pues les es financieramente imposible. En la mayoría de los casos el estudio es revendido por la empresa que lo compra inicialmente. Si bien es cierto que, por lo general, el mercado solicita solo un estudio, cabe aclarar que en Colombia son varias las empresas que prestan estos servicios: Ibope Colombia, S.A.S.; Infometer, Medición electrónica de rating en televisión; Infoanálisis, Competencia publicitaria; Target Group Index (TGI); Mediciones y Medios S.A.; la Asociación Colombiana de Investigación de Medios (ACIM), entre otros.

\section{B. Conducta}

Desde 1995, año en el cual lbope, empresa que comercializaba sus servicios a través de contratos individuales, comenzó a realizar el estudio de medios en Colombia, y hasta el 31 de marzo de 2009, la investigación de medios era parte esencial de su iniciativa empresarial. Hasta ese momento se llevaba a cabo una sola medición en el mercado, hecha por Ibope, para la cual se establecieron unas normas mínimas, por la industria publicitaria, a través del Cicma. ${ }^{10}$ Dicho estudio era de propiedad de la empresa medidora (Ibope), empresa que lo vendía a cualquier interesado con tarifas establecidas en función del Target Rating Point (TRP).

En 2008, Ibope presentó un estudio de medición de audiencia de televisión por cable. En dicho estudio se reportaba un aumento del 67 $\%-60 \%$, correspondiente a los canales internacionales, y 7 \% a la televisión comunitaria-, lo que habría representado una disminución en los niveles de audiencia de los canales nacionales privados y, como consecuencia, la pérdida de valor de los puntos de rating que se cobran por la pauta publicitaria transmitida. Frente a esto, Caracol y RCN se opusieron alegando que había defectos en el estudio, pues los resultados no reflejaban la dinámica real del mercado. En consecuencia, contrataron a una persona especializada para que revisara el estudio, quien concluyó que este era correcto. Ante esta situación, Caracol, RCN y la Unión Colombiana de Empresas Publicitarias (UCEP) hicieron una convocatoria privada para elegir una empresa que hiciera nuevamente el estudio. A esta convocatoria se presentó Ibope, y fue elegida. Ahora, para el nuevo negocio entre Caracol, RCN y la UCEP, e Ibope, se celebró un contrato en el que se estipuló que aquellos decidirían a quién se revendía el estudio, a qué precio, con qué metodología y cómo se auditaba. En el contrato se

10 Comité Intergremial Colombiano de Medición Electrónica de Audiencia. 
pactaba: i) Ibope se comprometía a realizar las mediciones de audiencias y valoraciones publicitarias del país, estudio que, de conformidad con el contrato celebrado, no podría ser vendido ni cedido a ningún título, ni en Colombia ni en el exterior, sin el consentimiento previo y expreso de RCN, Caracol y la UCEP; ii) Ibope llevaría a cabo el estudio de medición desde el primero de abril de 2009 hasta el 31 de marzo de 2011, estudio del que sería titular de la nuda propiedad, y entregaba el uso y usufructo de los mismos a RCN, Caracol y la UCEP, y iii) RCN, Caracol y la UCEP definirían las condiciones y requerimientos de la medición que debía cumplir Ibope.

\section{Análisis de la SIC}

Por medio de la Resolución 23890/2011 la SIC se pronunció sobre el caso, para el cual había abierto investigación formal a través de la Resolución 20065/2010. La SIC decidió imponer sanciones a Caracol, RCN, UCEP e lbope basándose en las siguientes razones. La primera, Caracol, RCN, la UCEP e Ibope tenían posiciones privilegiadas o representativas dentro de los mercados involucrados en el caso, y, en consecuencia, obtuvieron una ventaja competitiva ilícita derivada de la suscripción del acuerdo, y siguieron conservando dichos privilegios de posicionamiento (SIC, Resolución 23890). La segunda razón fundamental en la decisión de la SIC se basa en que, según los testimonios allegados como material probatorio, se logró concluir que los productos ofrecidos por lbope no tenían sustitutos, debido a las características tecnológicas de los servicios que prestaba esta empresa en el momento de los hechos, puesto que sus estudios eran muy exactos y completos gracias a su tecnología avanzada. Para llegar a esta conclusión, la SIC analizó las características, usos y precios de los estudios que miden el rating de televisión en Colombia, y establecieron que no había sustitutos por las especificidades técnicas de cada estudio. Sin embargo, se aceptó la presencia de otros oferentes de productos de medición de rating que participaban en el mercado para ese entonces.

Otra razón expuesta por la SIC es que, de acuerdo con el material probatorio recaudado, se pudo demostrar que, como resultado del acuerdo establecido entre las partes, hubo efectos anticompetitivos verticales en el mercado de medición de audiencia de televisión, y horizontales en el mercado de pauta publicitaria. Para esto se demostró que, aunque se trata de mercados independientes, hay una fuerte relación entre ambos, pues los bienes y servicios finales del mercado de medición de audiencia son considerados insumos esenciales para la determinación del precio en el mercado de la pauta publicitaria.

\section{Análisis del caso a la luz de los conceptos expuestos}

El análisis de la SIC carece de argumentos sólidos que conlleven la sanción de los agentes involucrados. Los conceptos teóricos se entremezclan y se confunden los dos mercados involucrados como si fuese uno solo. Resulta dispendioso hacer un análisis de cuáles fueron las verdaderas razones por las cuales la SIC tomó 
su decisión, pues en los casos de restricciones verticales se deben evaluar muchos elementos y se puede perder la esencia del análisis; no solo importa si hay o no acuerdos o posición dominante para determinar una sanción, se requiere también el análisis de otros elementos más específicos. Debido a esto, se proponen aquí criterios básicos que deberían ser tenidos en cuenta por cualquier entidad que evalúe un caso específico: i) el mercado relevante; ii) la posición de dominio; iii) la presencia de un acuerdo; iv) la contestabilidad del mercado, y v) un examen de la industria específica. El siguiente es un análisis más detallado del caso lbope, basado en los criterios sugeridos.

i. Mercado relevante: Sobre este aspecto el análisis de la SIC no es muy preciso, pues no se establece con exactitud cuál es el mercado del producto y cuál es el mercado geográfico. A pesar de esta falencia, se entiende que el mercado geográfico es todo el territorio nacional, pues el estudio se hace para el territorio colombiano. La referencia al mercado geográfico, en este caso, resulta importante desde la perspectiva de la oferta, pues pueden entrar al mercado colombiano nuevos competidores que presten los mismos servicios que Ibope, y, por lo tanto, haya sustituibilidad de la oferta desde el punto de vista geográfico. Esto es posible, pues a nivel internacional hay varias empresas dedicadas a la medición del rating, tal y como se expone en la Resolución 20065, que pueden incorporar tecnologías más sofisticadas, e incluso a menores precios. Por lo tanto, evaluar el mercado geográfico de lbope puede influir en las consideraciones finales sobre la anticompetitividad del acuerdo. En cuanto a la definición del mercado de producto de Ibope, la SIC hizo un análisis cuidadoso, aunque no suficiente, pues si bien estableció que debido a las características especiales del producto ofrecido por Ibope no había sustituibilidad en la demanda, no se detuvo a evaluar la posibilidad de que empresas como Nielsen, activa en el mercado, ofrecieran productos similares. De hecho, esta posibilidad se señala en algunos de los testimonios que conforman el acervo probatorio del proceso, pero no se tiene en cuenta por la superintendencia en su decisión.

ii. Posición de dominio: Frente a esto el análisis de la SIC es detallado, pues afirma que Ibope goza de posición de dominio en el mercado de medición de audiencia, ya que su producto, Infoanálisis, se ha convertido en un "insumo esencial". Sin embargo, en la exposición de argumentos la SIC se contradice en dos aspectos. Primero, afirma que no hay más competidores en el mercado que ofrezcan productos de medición de rating, cuando desde el principio se establece que sí hay más oferentes. Entre estos se encuentran Ibope Colombia, S.A.S.; Infometer, Medición electrónica de rating en televisión; Infoanálisis, Competencia publicitaria; Target Group Index (TGI); Mediciones y Medios, S.A.; Asociación Colombiana de Investigación de Medios (ACIM), entre otros. Por lo tanto, no hay un único proveedor del producto, como se afirma en la decisión. La segunda contradicción es no tener en cuenta dos mercados diferentes e independientes, pues la SIC habla indiscriminadamente de dos mercados como si fuese uno solo. Si bien en un principio se establece la di- 
ferencia entre el mercado de la pauta publicitaria y el mercado de medición de audiencia, más adelante se confunden estos dos mercados y se establece que solo hay un acuerdo vertical con efectos horizontales y verticales. Este es un punto fundamental para definir un acuerdo vertical, pues el primer paso es definir cuál es el mercado y cuáles los agentes involucrados. Sin embargo, cabe aclarar que aunque son dos mercados diferentes, no son independientes, pues el bien comercializado en el mercado de medición de audiencia es un bien necesario para el mercado de pauta publicitaria.

iii. La presencia de un acuerdo: En el análisis de la SIC se aborda este punto a cabalidad y sin imprecisiones, pues desde el principio se deja claro que sí hay un acuerdo entre dos partes, Ibope, por un lado, y RCN, Caracol y la UCEP, por el otro. Además, se exponen cuáles fueron las condiciones de dicho acuerdo y por qué se presume anticompetitivo.

iv. Contestabilidad del mercado: Como se expuso al hablar sobre el mercado relevante, la sustituibilidad de la oferta solo se menciona de manera superficial en el análisis, a pesar de que varias pruebas muestran la potencialidad para que empresas internacionales se introduzcan en el mercado y ofrezcan productos que cumplan con las mismas condiciones que los estudios de lbope, o que empresas que ya están en el mercado ofrezcan productos sustitutos, como es el caso del producto de Nielsen. Si este análisis se hubiera hecho, la decisión, posiblemente, habría sido diferente. v. Análisis de la industria específica: En Colombia, varias directrices guían la industria publicitaria, la mayoría de las cuales surgen de la iniciativa privada. Hay, por ejemplo, entidades como la Comisión Nacional de Autorregulación Publicitaria (Conarp), fundada por representantes de la Unión Colombiana de Empresas Publicitarias (UCEP), la Asociación Nacional de Anunciantes (ANDA) y la International Advertising Association (IAA). Actualmente, la autoridad nacional en esta materia es la Autoridad Nacional de Televisión (ANTV). Sin embargo, para el momento de los hechos esta potestad estaba en cabeza de la Comisión Nacional de Televisión (CNTV). En materia de regulación, la entidad encargada es la Comisión Nacional de Comunicaciones. Además, hay un instrumento normativo que recopila algunas normas sobre la materia: el Código de Autorregulación Publicitaria.

Si bien esta normatividad se tuvo en cuenta en el análisis, se omite mencionar qué dicen estas disposiciones sobre los estudios de rating. En ninguna regulación se señala la necesidad de estos estudios como insumo esencial. De forma que exigirle a una empresa privada, y a quienes invierten en sus productos, que compartan la información por la que están pagando, genera desincentivos para que en un futuro esta empresa vuelva a comprar el producto o a tomar la iniciativa de hacerlo. Esto desemboca en un caso de free-riding, en el que solo dos empresas pagan por un producto, y el resto de agentes se benefician de esta inversión sin ninguna clase de esfuerzo. Para que esto se pueda exigir sin que se generen desincentivos, debe haber regulaciones que así lo dispongan. 
En suma, un análisis un poco más riguroso teniendo en cuenta los elementos propuestospuede llevar a la conclusión de que si bien hay un acuerdo, no es ineficiente por tres razones. Primero, se trata de dos agentes privados haciendo negocios de compraventa de un producto en el que hay una contraprestación económica a favor de Ibope, empresa encargada de crear el producto. Es un negocio jurídico como cualquier contrato, en el cual Ibope, simplemente, ofrece su producto, un comprador interesado paga el precio requerido $y$, finalmente, adquiere los derechos sobre el producto. Segundo, si otros agentes tuvieran acceso al bien a un precio menor que el que tuvieron que pagar los compradores iniciales, llevará a un caso de freeriding, pues ninguna regulación estipula que los que tengan que correr con los costos sean Caracol, RCN y la UCEP. Tercero, si Caracol, RCN y la UCEP tuviesen que cubrir los costos del estudio, se generarían desincentivos para la inversión en esta clase de productos, pues la próxima vez no invertirán este dinero porque otros, sin pagar por ello, se beneficiarán. Por último, es preciso aclarar que el hecho de exigir una contraprestación por la comercialización del estudio -sobre el que tienen derechos patrimoniales RCN, Caracol y la UCEP- no genera una carga económica mayor en cabeza de los demás agentes que lo compren, puesto que lo exigido por RCN, Caracol y la UCEP para vender un estudio -que es de ellos- es mucho menor de lo que ellos pagaron. En el caso Ibope, el problema principal es que no hay una regulación específica que determine que el producto Infoanálisis funciona como insumo esencial del mercado, y una que regule cómo debe repartirse la información.

\section{LINEAMIENTOS QUE SE DEBERÍAN TENER EN CUENTA PARA EL ANÁLISIS DE CASOS}

El análisis de la decisión de la SIC sobre el caso Ibope sugiere que es más útil, y puede llevar a una decisión más concreta en casos de restricciones verticales, hacer un evaluación más estructurada en la que, al menos, se tengan en cuenta los cinco elementos propuestos: mercado relevante, posición de dominio, presencia de un acuerdo, contestabilidad del mercado y análisis de la industria específica.

Se debe establecer si, efectivamente, hay posición dominante en cabeza de los agentes económicos involucrados en la supuesta práctica restrictiva de la competencia. En este punto se debe tener en cuenta que, tal y como se expuso, la posición dominante no es únicamente formal, es decir, concerniente a las cuotas del mercado de la empresa, sino que puede haber posición de dominio, en sentido material, según la influencia que tenga la empresa en el mercado, ya sea porque su producto cuenta con características únicas, y por el reconocimiento que tiene en la industria, entre otras razones. El resultado de este análisis justificará la intervención de la SIC si la conducta es relevante, o la no intervención, si es una conducta inocua para el mercado. La SIC tiene la facultad de decidir si abre una investigación o no. Ahora, una vez hecho esto, se deberá analizar si hay un acuerdo, en los términos del Decreto de 1992, y de qué tipo de acuerdo se trata. Es decir, además de identificar la presencia del acuerdo, se debe es- 
tablecer si efectivamente se trata de un acuerdo vertical, teniendo presente la estructura del mercado y las relaciones entre los agentes involucrados. Hecho esto, se deben analizar los efectos potenciales del acuerdo en la dinámica del mercado.

El siguiente criterio que se debería tener en cuenta es el análisis del mercado relevante del producto y el mercado geográfico. Este criterio ayudará a determinar la falta de sustitutos dentro de la demanda, y si tampoco los hay dentro de la oferta, de forma que se defina si, efectivamente, hay grandes limitaciones en el mercado que restrinjan la competencia en un grado tal que la restricción vertical genere efectos anticompetitivos. En este punto se debe prestar especial atención a la sustituibilidad de la oferta, pues comúnmente el análisis se centra más en la demanda, subestimándose los efectos que puede tener la falta de barreras de entrada a otros competidores.

Esto último se relaciona con el siguiente criterio, la contestabilidad del mercado, pues si hay sustituibilidad de la oferta se puede demostrar que es posible que haya una amenaza latente de entrada de nuevos competidores, o de nuevos productos ofrecidos por los agentes que ya se encuentran en el mercado. En este sentido, analizar si el mercado es o no contestable es fundamental para determinar si el acuerdo puede o no viciar la competencia, pues, en algunos casos, a pesar de la posición de dominio, de la no sustituibilidad de la demanda y de la presencia de un acuerdo, la amenaza de entrada de nuevos competidores sugiere que es posible que tal acuerdo no genere ineficiencia ni restricciones en la competencia del mercado.

Por último, se debe analizar cómo es el funcionamiento del mercado específico. Esto incluye el análisis de la legislación del sector, la regulación que ha surgido por la iniciativa privada o gubernamental, las costumbres sectoriales, y los demás factores relevantes que ayuden a determinar si el acuerdo puede funcionar a favor de la eficiencia del mercado.

La propuesta de los criterios para estudiar cada caso específico sobre restricciones verticales sugiere que el análisis debe tener un énfasis casuístico; no debe acudirse a reglas inexistentes en nuestro ordenamiento jurídico, como la ilegalidad per se.

\section{CONCLUSIONES}

- En el ordenamiento jurídico colombiano no se han acogido las teorías adoptadas en otros países para el análisis de casos sobre acuerdos potencialmente restrictivos de la competencia, como la ilegalidad per se y la regla de la razón.

- En Colombia, la legislación que se tiene en cuenta para las restricciones verticales es la de los acuerdos en general, pues no hay una norma que discrimine entre acuerdos verticales $u$ horizontales.

- Hay restricciones verticales que pueden ser favorables para la eficiencia del mercado, pues tienen como fin maximizar el beneficio; no buscan entorpecer la competencia, aun cuando se 
limita, en algún grado, la libertad de las partes. En el caso Ibope, el acuerdo evitaba que se diera un caso de free-riding, que desincentivaría la inversión en el mercado.

- Para un análisis completo de un caso de restricciones verticales se deben tener en cuenta cinco criterios: i) la presencia de posición de dominio; ii) la presencia de un acuerdo; iii) el establecimiento del mercado relevante; iv) el análisis de la contestabilidad del mercado, y v) el análisis de la industria específica.

\section{Referencias}

Agostini, C. Mercado contestable. Recuperado de http://www.blogeconomia.uahurtado. $c l / p=25$.

Almonacid Sierra, J. y García Lozada, N. G. (1998). Derecho de la competencia. Bogotá: Legis.

Baumol, W. (1982). Contestable Markets: An Uprising in the Theory of Industry Structure. En The American Economic Review, 72 (1), 1-15. Recuperado de http://www.jstor.org/ stable/1808571.

Butz, D. y Kleit A. (2012). Are Vertical Restraints pro or anticompetitive? En Chicago Journals 44 (1), 131-160. Recuperado de http:// www.jstor.org/stable/10.1086/320277.

Concepto 23410 de 2000, SIC.
Constitución Política de Colombia, artículo 333. Recuperado de http://www.banrep.gov.co/ regimen/resoluciones/cp91.pdf.

Corte Constitucional, Sentencia T-240 de 1993

Crew, M. y Kleindorger, P. (1986). The Economics of Public Utility Regulation. The MIT press, 10.

Decreto 2153 de 1992, artículo 45, Ministerio de Desarrollo Económico.

Díez, F. (2001). Algunas consideraciones en torno a la comunicación sobre definición de mercado relevante de la Comisión Europea y las Merger Guidelines del Departamento de Justicia de EE. UU. En Anuario de la competencia, 321-349.

Federal Trade Commission. Toys "R" Us, Inc., Petitioner-Appellant, v. Federal Trade Commission, RespondentAppellee. Recuperado de http://www.ftc. gov/os/adjpro/d9278/toysrusvftc.shtm.

Irarrázabal, F. (25 de octubre de 2012). FNE raya la cancha a empresas por restricciones verticales, comunicación personal. Recuperado de http://www.estrategia.cl/detalle_noticia. php?cod=66575.

Guía sobre la aplicación de las normas de competencia frente a los acuerdos de colaboración entre competidores, SIC.

Jiménez, F. y Cañizares, E. (2005, octubre). Dificultades para la definición del mercado rele- 
vante. Preparado para el Segundo Seminario de Derecho y Economía de la Competencia, Fundación Rafael del Pino, Madrid.

Kwowa, L. y White J. (2009). The antitrust revolution: Economics, Competition and Policy. 5. ${ }^{\text {a }}$ edición. Oxford: Oxford University Press, 353.

Ley 155 de 1959. Recuperado de http://www. alcaldiabogota.gov.co/sisjur/normas/Norma1.jsp?i=38169.

Mankiw, G. (2004). Principios de economía. 3. ${ }^{\text {a }}$ edición. Cambridge: Mc Graw-Hill.

Memoria jurídica de 2011, SIC.

Motta, M. (2009). Competition Policy: Theory and Practice. Cambridge: Cambridge University Press.

Organización de Cooperación y Desarrollo Económico (OCDE) (2009). Derecho y Política de la Competencia en Colombia: Examen interpares.

Rey, P. (2008). Economics of Vertical Restraints.

En The MIT Press, 353-390.
Salamanca, M. Restricciones verticales y abuso de posición dominante: Jurisprudencia de las comisiones antimonopolio. Chile: Fiscalía Nacional Económica.

Shy, O. (2005). Industrial Organization: Theory and Applications. En The MIT press, 389.

Superintendencia de Industria y Comercio, Resolución 0670 de 2001.

-, Resolución 21821 de 2004.

-, Resolución 23650 de 1999.

-, Resolución 23652 de 1999.

-, Resolución 23890 de 2011.

-, Resolución 7950 de 2002.

_, Resolución 8233 de 2001.

Williams, W. (2012). Qué o quién es el mercado. Recuperado de http://www.scbbs.com.bo/ craigs/Libib/mercado.html. 
ANEXO 1

Figura 1. Estructura del mercado de la pauta publicitaria de acuerdo con la Resolución 290065 de la SIC.

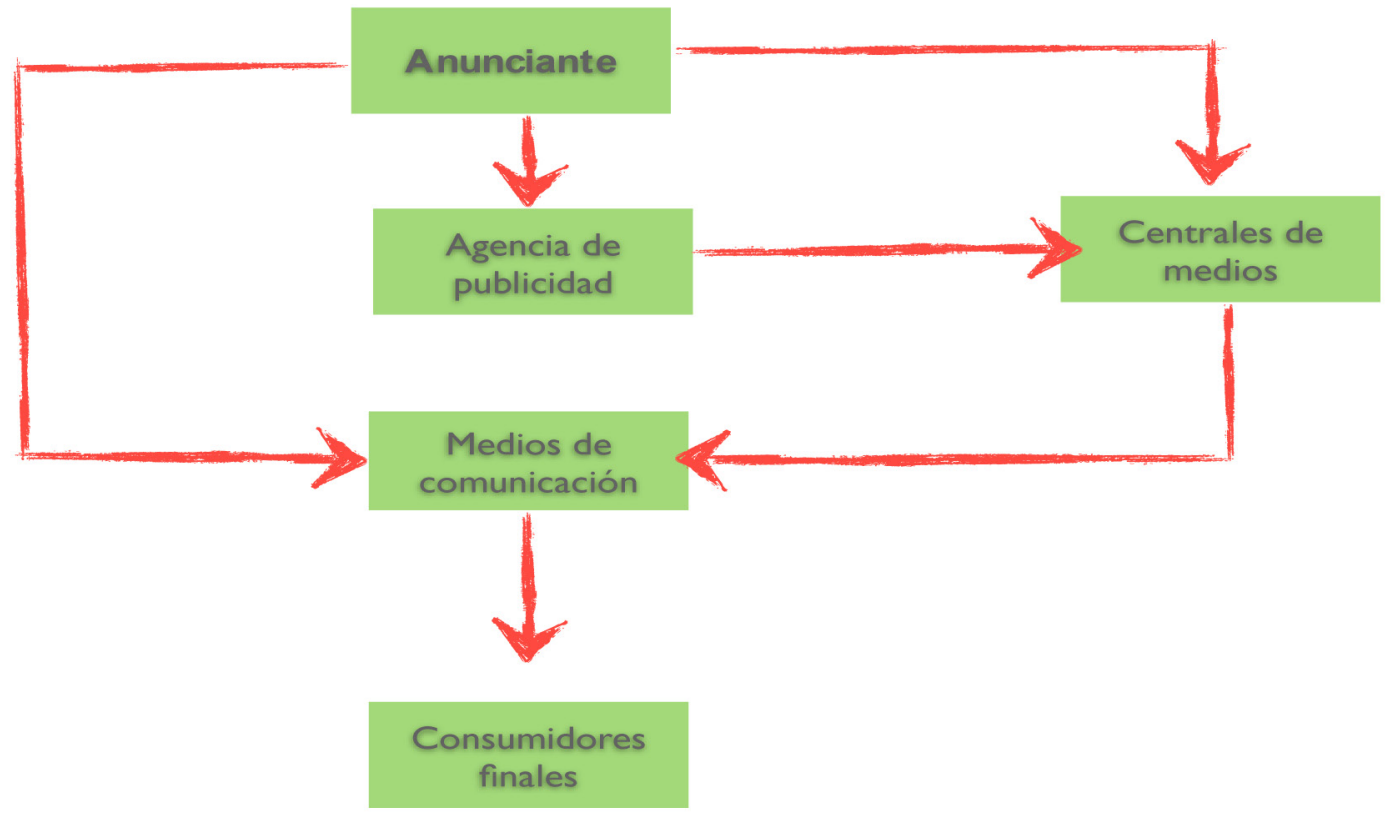

Figura 2. Estructura del mercado de medición de audiencia de televisión de acuerdo con la Resolución 20065 de la SIC.
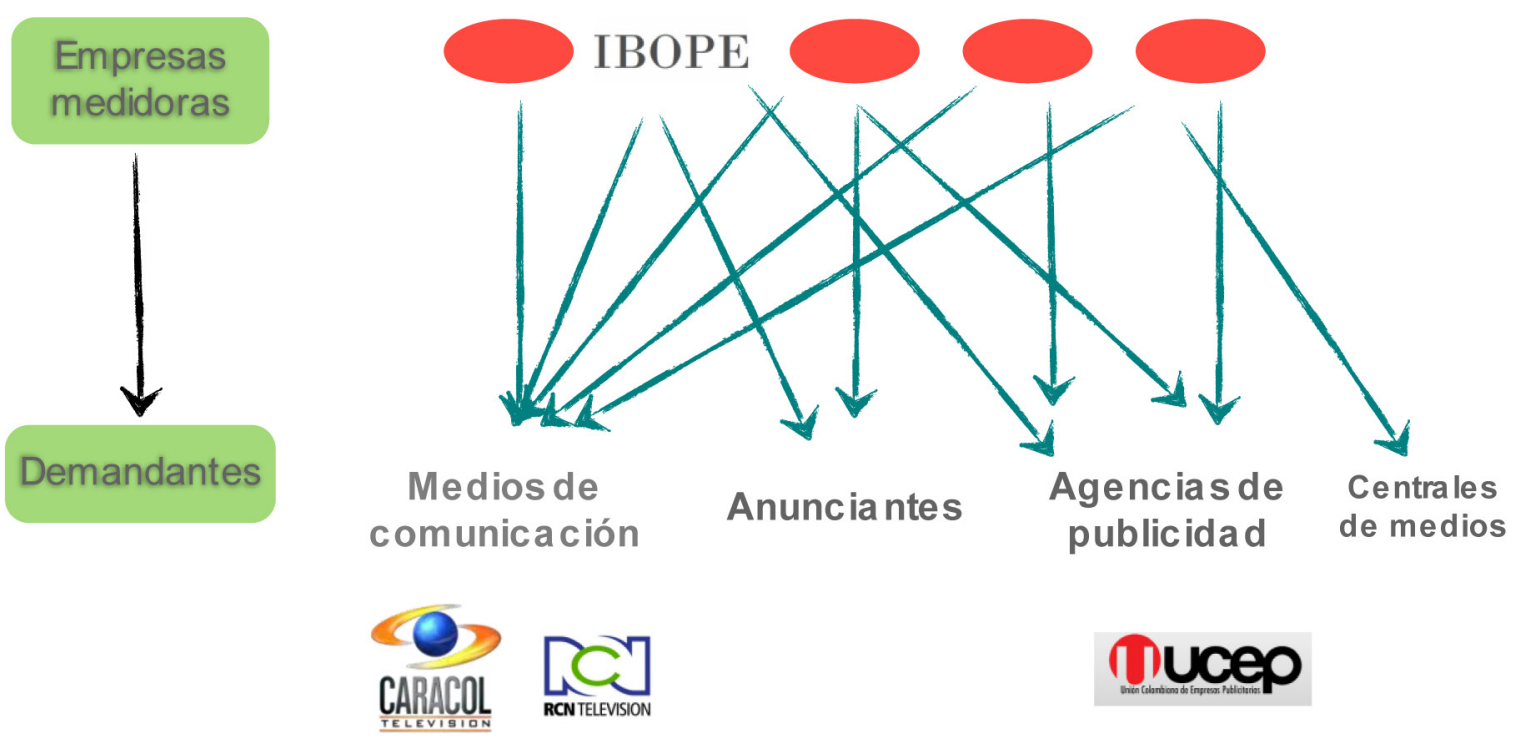